\title{
In memory of Arthur Ashkin
}

\author{
Radiation pressure exerted by light was a lifelong passion for Arthur Ashkin. He foresaw that light pressure could \\ do useful work and invented the optical tweezers that can trap microscopic objects, from small 'living things' down \\ to individual atoms.
}

B orn on 2 September 1922, the son of immigrants from Eastern Europe, Arthur Ashkin (pictured) was always proud of his humble heritage. Despite not having been raised in a scholarly environment, he possessed an almost limitless passion for learning that lasted until his passing on 21 September 2020.

At ten years old, Ashkin was fascinated by the Crookes radiometer. He would bring it to sunlight to observe the vanes turning. He learned a few years later that this behaviour was due to the thermal forces from the air remaining in the glass bulb. He also found out that, with a higher level of vacuum, the vanes would turn in the opposite direction due to radiation pressure. It was the first time Ashkin became aware that radiation pressure could do useful work. His desire to understand the Crookes radiometer ultimately led him to demonstrate the optical tweezers at the age of 63. It is this invention that won him the 2018 Nobel Prize in Physics.

Art, as he was known to friends and colleagues, was raised in Flatbush, a neighbourhood in New York City's Brooklyn borough. His father, Isador, was an orphan from Odessa, then part of Russia. His mother, Anna, emigrated in early childhood from Galicia, then part of the Austro-Hungarian Empire. Art's last name, Ashkin, a shortened version of the original Ashkenasy, was the creation of an immigration officer when Isador arrived at Ellis Island in 1910 as a young man. Art grew up with his brother, Julius, and sister, Ruth. An older sister, Gertrude, died at a young age. Julius was two years Art's senior. Julius became a notable physicist at a very young age and played an important role in the Manhattan Project. The 'Ashkin' in the Ashkin-Teller model refers to Julius. In the early days of the brothers' careers, leading physicists who worked with Julius sometimes referred to Art as 'Ashkin's brother, Ashkin'.

The United States' involvement in World War II interrupted Art's undergraduate studies in physics at Columbia University. He was drafted into the Signal Corps, a division of the US Army. Starting in 1942, he worked as a technician on the rising sun magnetron $^{1,2}$ as part of the war effort at

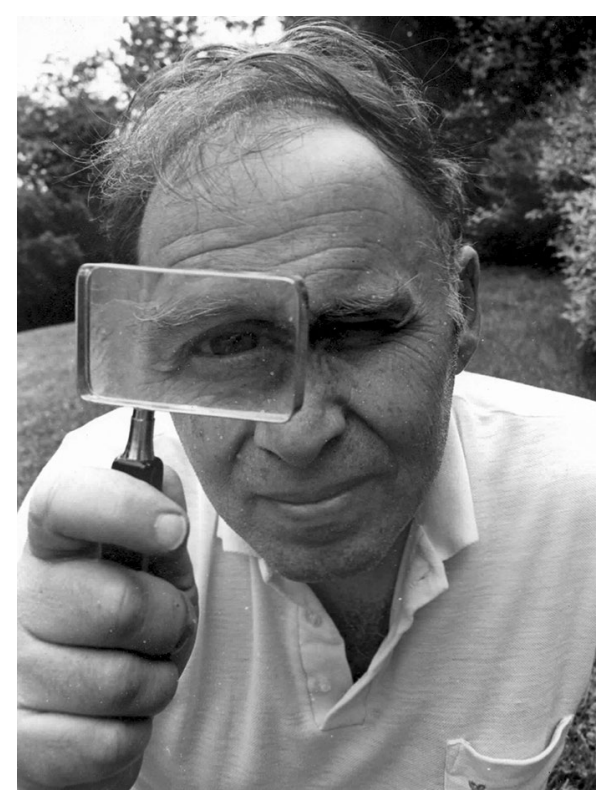

Arthur Ashkin in his garden around 1975

Courtesy of Daniel Ashkin.

the Columbia Radiation Laboratory under the supervision of Sidney Millman. The high-power magnetron was intended to be used in radar.

Art started at Bell Labs in 1952, immediately after obtaining his $\mathrm{PhD}$ from Cornell University in nuclear physics. He joined the microwave research department at the Murray Hill Laboratory, where he was focused on improving the travelling-wave tube amplifier. His first experiments in optics started around 1962, a few years after the laser was demonstrated. A series of discoveries and inventions followed. He is credited with the discovery of the optical damage created by the photorefractive effect in lithium niobate and lithium tantalate ${ }^{3}$. He also was the first to observe second-harmonic generation from a continuous-wave signal at optical frequencies ${ }^{4}$.

From the mid- to late-1960s, Arthur hired three young researchers, John Bjorkholm, Roger Stolen and Erich Ippen. In the decade that followed, under Art's supervision and guidance, they performed experiments that laid the foundation of nonlinear optics in fibres. Such phenomena as stimulated Brillouin and Raman scattering in fibres and four-wave mixing, sometimes referred to as four-photon mixing at the time, were first demonstrated ${ }^{5}$ by Art's group.

In 1966, Art attended a presentation by Rawson, Hara and May at the International Quantum Electronics Conference (IQEC) in Arizona, where they showed a video on 'runners and bouncers', small particles that moved around seemingly at random inside a laser cavity ${ }^{6,7}$. The motion was quickly identified as being of thermal origin, but this demonstration reignited Art's childhood desire to demonstrate that radiation pressure could do useful work if thermal effects could be suppressed.

It was in 1969 that Art observed for the first time that radiation pressure can trap small dielectric spheres. He published his findings in a milestone paper in Physical Review Letters, but not without difficulties. The challenge did not come from the journal but from a mandatory internal review at Bell Labs. That review stated that the manuscript was not worthy of Physical Review Letters. Despite this obstacle, the manuscript, submitted in its original form, was easily accepted and is considered by most as signalling the birth of optical trapping by radiation pressure ${ }^{8}$. Art also discussed trapping of atoms using radiation pressure in that paper.

The next year, Art demonstrated optical levitation where radiation pressure is used to compensate gravity ${ }^{9}$. Recognizing that optical levitation can be used as a sensitive detection mechanism, Art used this tool to optically measure the charge of the electron and to perform very precise measurements of Mie scattering and of the dimensions of objects $^{10}$.

Optical trapping of atoms employing radiation pressure remained an overarching goal for Art. Together with John Bjorkholm and his long-time technical assistant and friend, Joseph Dziedzic, he performed a series of experiments towards that goal ${ }^{11}$. They were joined by Steven Chu in the early 1980s. After another series of breakthrough experimental realizations, stable atom trapping was achieved. This achievement was part of the scientific discoveries on atom trapping and cooling that led to the 1997 
Nobel Prize in Physics being awarded to Steven Chu, Claude Cohen-Tannoudji and William Phillips.

The basic concept that led to the optical tweezers came to Art in $1977^{12}$, and he demonstrated it with his colleagues in $1985^{13}$. The idea that an object can be stably trapped in space within a single laser beam may appear counterintuitive at first. Art had demonstrated in 1969 that a transparent sphere could be trapped in the transverse direction of a laser beam due to its transverse gradient of intensity. The sphere, however, experienced a net forward force due to light scattering off the sphere that pushed it in the same direction as the laser. To provide a confinement in the axial direction of the laser, Art realized that by tightly focusing the beam with a strong lens, one creates a large axial intensity gradient over a short distance just beyond the focal point. That gradient produces a backward gradient force that compensates the forward scattering force. The result is a three-dimensional optical trap created within a single laser beam. He called his invention the optical tweezers and he was awarded the 2018 Nobel Prize in Physics "for the optical tweezers and their application to biological systems".

Art had trapped spherical objects with his optical tweezers but it remained unclear if objects of irregular forms could be 'captured' as easily by the tweezers. Art and Dziedzic decided to try trapping the Tobacco Mosaic Virus (TMV) that has a rod-like shape, about 16 times longer than its diameter. Fortunately, they were able to grab the virus by either end and stabilize it. During that study, the TMV samples were left exposed to the air and became contaminated with bacteria that were found inadvertently trapped inside the optical tweezers. To the surprise of Art and Dziedzic, the bacteria remained alive in the trap for several minutes. If the power of the green laser used for trapping was increased, there would be a "wild display of light scattering" before it settled down to a steady state and the bacterium would die by 'opticution', a term coined by Art to mean death by light. A change of wavelength from the 514.5-nm visible green laser to a $1.06-\mu \mathrm{m}$ infrared yttrium/aluminium laser where bacteria absorb less light enabled bacteria to be kept alive for hours. It even allowed cell reproduction within the optical trap to be observed. Following this serendipitous trapping of bacteria, Art and Dziedzic went on to trap and study all kinds of living things, including chloroplasts, spermatozoa, organelles of the paramecium and the giant amoeba Reticulomyxa ${ }^{14}$. These experiments led to the development of new applications of optical tweezers in biology. It became possible to study very precisely the interactions of individual biological molecules, including $\mathrm{DNA}^{14}$.

The exceptional experimental skills of Art were well known at Bell Labs. He was often consulted by colleagues on how to perform difficult experiments. He had a bag of tricks like no other. For instance, he invented a free-space polarization-independent variable optical attenuator based on diffraction on a metallic comb ${ }^{15}$. The attenuation of a laser beam could be varied continuously from transparency to in excess of $30 \mathrm{~dB}$. It could handle high continuous-wave powers and produce high-quality beams.

Art saw himself as an inventor first. He enjoyed 'playing with toys' and finding ways in which they can be made useful. The last 15 years of his life were devoted to studying ways to harness the energy of the Sun at low cost, with the hope of reducing global warming and improving the quality of life in developing countries. Arthur Ashkin was a remarkable inventor and scientist who cared deeply about people and who was beloved by his colleagues.

\section{René-Jean Essiambre (D)}

Murray Hill Laboratory, Bell Labs, Nokia, New

Providence, NJ, USA.

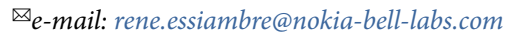

Published online: 19 February 2021

https://doi.org/10.1038/s41566-021-00768-0

\section{References}

1. Ashkin, A. Phys. Rev. 69, 701 (1946).

2. Millman, S. \& Nordsieck, A. T. J. Appl. Phys. 19, 156-165 (1948).

3. Ashkin, A. et al. Appl. Phys. Lett. 9, 72-74 (1966).

4. Ashkin, A., Boyd, G. D. \& Dziedzic, J. M. Phys. Rev. Lett. 11 14-17 (1963).

5. Stolen, R. H. J. Light. Technol. 26, 1021-1031 (2008).

6. Rawson, E. G., Hara, A. H. \& May, A. D. In Proc. International Quantum Electronics Conference 8C-3 (OSA, 1966).

7. Rawson, E. G. \& May, A. D. Appl. Phys. Lett. 8, 93-95 (1966).

8. Ashkin, A. Phys. Rev. Lett. 24, 156-159 (1970).

9. Ashkin, A. \& Dziedzic, J. M. Appl. Phys. Lett. 19, 283-285 (1971).

10. Ashkin, A. Science 210, 1081-1088 (1980).

11. Ashkin, A. Proc. Natl Acad. Sci. USA 94, 4853-4860 (1997).

12. Ashkin, A. Phys. Rev. Lett. 40, 729-732 (1978).

13. Ashkin, A., Dziedzic, J. M., Bjorkholm, J. E. \& Chu, S. Opt. Lett. 11, 288-290 (1986).

14. Ashkin, A. Optical Trapping and Manipulation of Neutral Particles Using Lasers: A Reprint Volume with Commentaries (World Scientific, 2006).

15. Ashkin, A. Nonpolarizing wire-grid diffraction-type optical attenuator. US patent 3,620,599 (1969).

\section{Acknowledgements}

Many people contributed to this obituary. I would like to thank his wife Aline, his daughter, Judith Herscu, and sons, Michael and Daniel. Many thanks to R. Stolen, J. Bjorkholm, E. Ippen, G. Bjorklund and S. Harris who kindly provided feedback on the manuscript. 